\title{
Seismic Response of Prestressed Anchors with Frame Structure
}

\author{
Shuaihua Ye $\mathbb{D}^{1,2}$ and Zhuangfu Zhao ${ }^{1,2}$ \\ ${ }^{1}$ Key Laboratory of Disaster Mitigation in Civil Engineering of Gansu Province, Lanzhou University of Technology, \\ Lanzhou 730050, China \\ ${ }^{2}$ Western Center of Disaster Mitigation in Civil Engineering, Ministry of Education, Lanzhou University of Technology, \\ Lanzhou 730050, China
}

Correspondence should be addressed to Shuaihua Ye; yeshuaihua@163.com

Received 1 November 2019; Accepted 22 January 2020; Published 24 February 2020

Academic Editor: Andrea Alaimo

Copyright (C) 2020 Shuaihua Ye and Zhuangfu Zhao. This is an open access article distributed under the Creative Commons Attribution License, which permits unrestricted use, distribution, and reproduction in any medium, provided the original work is properly cited.

\begin{abstract}
Based on the equivalent mass-spring model and considering the coupling effect between creep soil and prestressed anchors, the dynamic calculation model of prestressed anchors with frame structure is established. The soil mass is expressed in the form of concentrated mass. The action of the frame structure on the soil is treated as a parallel coupling of a linear spring and a linear damper, and the free section of the anchor is treated as a linear spring. Considering the creep characteristics, the soil is regarded as a Generalized Kelvin body and the anchoring section of the anchor is regarded as an equivalent spring body, which are coupled in parallel. Considering the effect of slope height, the dynamic calculation model is solved and the seismic response is analyzed. Finally, an engineering example is used to verify the calculation method in this paper, and the results are compared with the shaking table test and numerical simulation. It shows that the calculation model proposed in this paper is safe and reasonable for the seismic design and analysis of the slope supported by prestressed anchors with frame structure.
\end{abstract}

\section{Introduction}

In the past, the traditional gravity retaining wall was used in the support technology of highway, railway, and building slope. These traditional retaining structures often have the disadvantages of insufficient stability and poor seismic performance. The analysis of slope stability and ground motion is still a hot topic in geotechnical engineering research. At present, some research results have been achieved on the design of flexible retaining structures. The supporting structure of prestressed anchors with frame is a new type of flexible supporting structure, which has been widely used in practical engineering. Under the seismic action, the interaction mechanism between the flexible retaining structure and the soil is extremely complicated. The seismic response of flexible support structures under seismic action still faces enormous challenges [1-6].

Based on the seismic response characteristics of flexible retaining structures, a series of assumptions are made to simplify the soil-structure system, so that the conventional dynamic calculation method can be applied to the dynamic analysis of the prestressed anchors with frame. At present, several studies have been published on the seismic design of supporting structures. Ye et al. [7] established the calculation model of the frameprestressed anchor-soil system under seismic action. Under the seismic action, the damping differential equation is established. The seismic response of the prestressing force and the anchorage axial force is solved under harmonic seismic loads. Considering the nature of the mutual influence between a structure and its supporting soil, Dong et al. [8] established a dynamic calculation model for slope stability of supporting frame with prestressed anchors. The vibration equation is derived, and the analytical solution under horizontal earthquake excitation is obtained. Considering the coupling relationship, Yan et al. [9] presented a proposed method for evaluating slope stability under seismic loads [10] that considers dynamic changes in the axial force of the anchor cables based on limit analysis and pseudodynamic methods. However, most of the dynamic calculation is based on the study of the overall calculation model of the slope system, which simplified the interaction between the supporting structure and soil. The spatial synergy of the frame-soil-anchor 
system cannot be clearly reflected, and the influence of the interaction between the soil and the anchor on the safety of the supporting structure is neglected. Therefore, it is necessary to establish a calculation model with spatial coordination, which takes into account both the frame-soil interaction and the soilanchor interaction and can reflect the creep characteristics of soil and the effect of slope height.

The equivalent mass-spring model was proposed in 1973 and was originally applied to the seismic design of tunnels $[11,12]$. The model assumes that the deformation of the structure is controlled by the deformation of the soil layer [13-15]. As shown in Figure 1, the soil layer is divided into many soil slices perpendicular to the tunnel. Each slice is represented by an equivalent mass-spring system that includes springs, dashpots, and lumped masses [16]. According to the characteristics of prestressed anchors with frame structure and based on the equivalent mass-spring model, the calculation model of frame-soil system can be established. Under the seismic action, the frame structure in the frame-soil system is mainly controlled by the soil behind the retaining wall. Although the existence of the frame structure also reacts on the soil, the deformation of the soil plays a leading role and the deformation of the frame needs to be coordinated with the soil [17].

Soil is a medium with complex mechanical properties with different elastic, plastic, and creep deformation properties under different stress conditions $[18,19]$. The creep characteristics of soil are mainly derived from its viscosity. Considering the creep characteristics of soil, the Generalized Kelvin model can be adopted (Figure 2). The Generalized Kelvin model can describe the viscoelastic-plastic characteristics of soil and is widely used in geotechnical theoretical analysis. Engineering practice and experimental analysis show that it is relatively consistent with the actual situation and has good applicability [20,21].

In this paper, based on the equivalent mass-spring model and considering the coupling effect of creep soil and prestressed anchors, the calculation model of prestressed anchors with frame structure is established. The soil mass is expressed in the form of concentrated mass. Considering the effect of frame structure, the action of the frame on the soil mass is treated as parallel coupling of a linear spring and a linear damper. The free section of the anchor is treated as a linear spring, and the soil is treated as a Generalized Kelvin style considering creep characteristics, which is coupled parallel to the equivalent spring of the anchorage section. Considering the effect of slope height, the prestress, axial force, and the acceleration response of anchors are solved. Finally, the results of shaking table test and numerical simulation are compared with the calculation method in this paper. The results show that the calculation model can be applied to slope support and design analysis.

\section{Establishment of the Dynamic Calculation Model}

The prestressed anchors with frame structure are a new type of support structure developed with the development of deep foundation pit and slope support technology. As shown

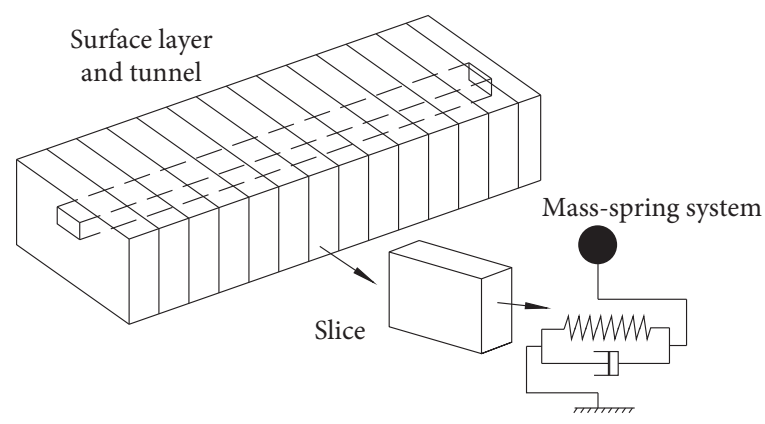

Figure 1: The equivalent mass-spring model.

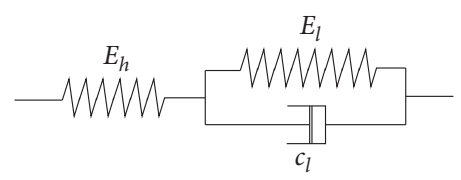

FIgURE 2: Generalized Kelvin model.

in Figure 3, it consists of frame, prestressed anchors, and soil behind the retaining wall, where the frame is composed of beams and columns, which is a lightweight structure.

In order to get the seismic response of the slope supported by the prestressed anchor with frame structure, the dynamic model of it must be established correspondingly. To make the problem easy to solve, it is necessary to simplify the structural system. Take a frame element and establish a model of slope supported by prestressed anchors with frame structure as shown in Figure 4. In order to describe the seismic response of prestressed anchors with frame structure, take a single anchor as the research object in this paper and finally establish a calculation model of prestressed anchors with frame structure as shown in Figure 5. For the convenience of establishment, the model of prestressed anchors with frame structure is regarded as a combination of the model of frame structure and prestressed anchor. The process of establishing the model is as follows.

2.1. Establishment of the Frame Structure. The seismic response of the frame structure is affected by the soil behind the retaining wall, and the soil behind the retaining wall is also affected by the frame. In the frame-soil system, the soil interacts with the structure. The inertia force of the frame has little influence on its dynamic form, which can be ignored in the analysis. In this case, taking the soil behind the retaining wall as the research object, the frame is regarded as an elastic foundation beam [8]. The deformation of the frame structure is coordinated with the deformation of the soil. The soil behind the retaining wall is cut into several slices along the height direction of the frame and expressed by equivalent concentrated mass.

The equivalent lump mass method: as shown in Figure 6, taking the anchor as the center, the mass of the soil in the sliding zone is concentrated by half of the vertical distance between the anchors and half of the horizontal distance between the anchors. Since the horizontal inclination angle of the anchor is generally small, the length of the center line of the soil in Figure 6 can be approximated as $L_{f} / \cos \alpha$, and the mass of the soil can be expressed as 


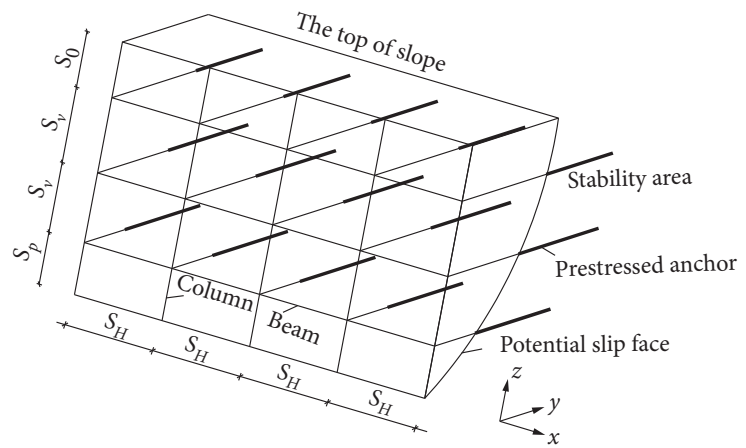

FIGURE 3: Slope supported by prestressed anchors with frame structure.

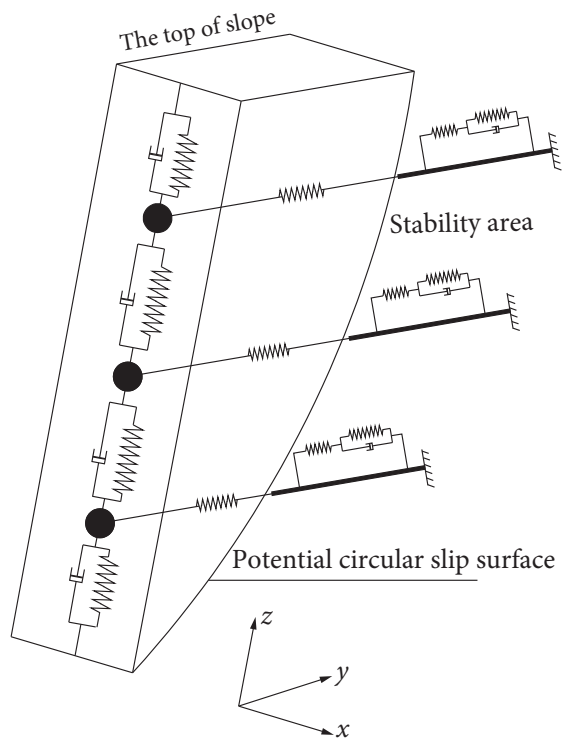

Figure 4: Model of slope supported by prestressed anchors with frame structure.

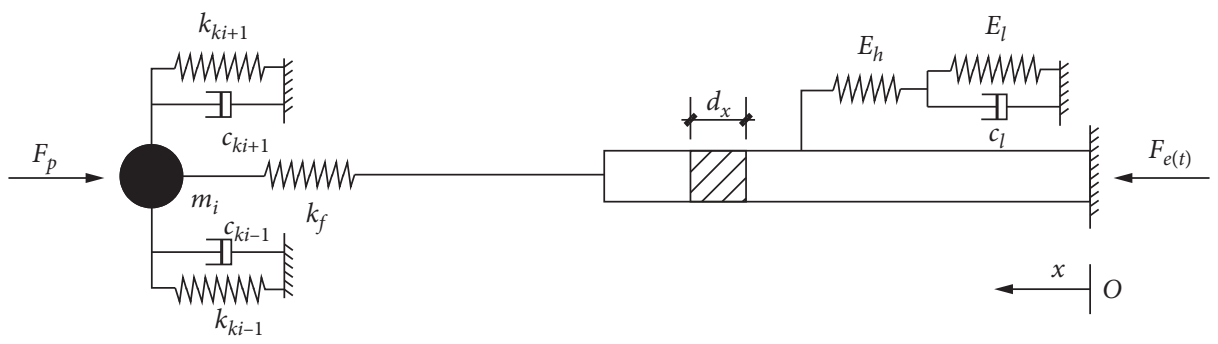

FIGURE 5: Calculation model of prestressed anchors with frame structure.

$$
\left\{\begin{array}{l}
m_{i}=\rho_{i} S_{H} S_{V} \frac{L_{f}}{\cos \alpha}, \quad i=2, \ldots, n-1, \\
m_{1}=\rho_{1} S_{H}\left(\frac{S_{V}}{2}+S_{0}\right) \frac{L_{f}}{\cos \alpha}, \\
m_{n}=\rho_{n} S_{H}\left(\frac{S_{V}}{2}+S_{p}\right) \frac{L_{f}}{\cos \alpha},
\end{array}\right.
$$

where $\rho_{i}$ is the soil density; $L_{f}$ is the length of the anchor's free section; $\alpha$ is the angle between the horizontal plane and the anchor; and $S_{V}$ and $S_{H}$ are the vertical spacing of beams and horizontal spacing of columns.

Based on the equivalent mass-spring model, the model of frame structure is established as shown in Figure 7. When establishing the calculation model of the frame structure, the following assumptions are made $[7,8,16]$ :

(a) In the process of slope vibration, the frame structure is in close contact with the soil behind the retaining wall without separation and slippage, and the deformation of the frame is synchronous with the soil. 


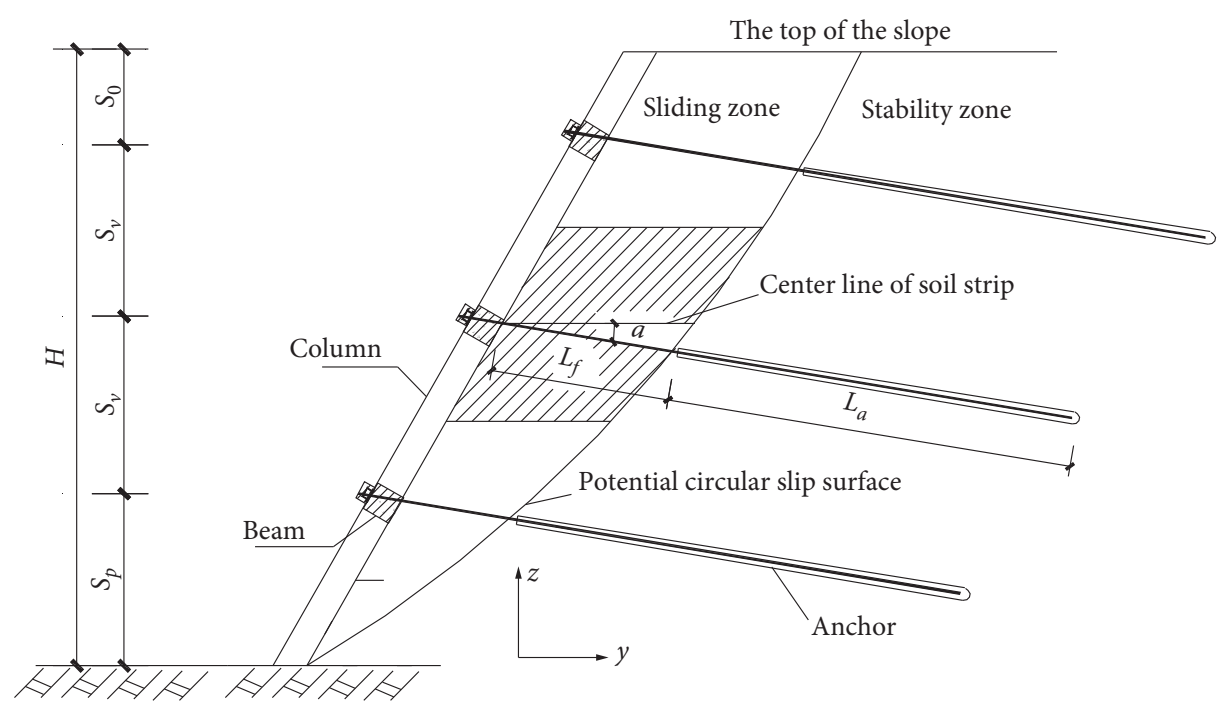

FIgURE 6: Calculation diagram of lumped mass.

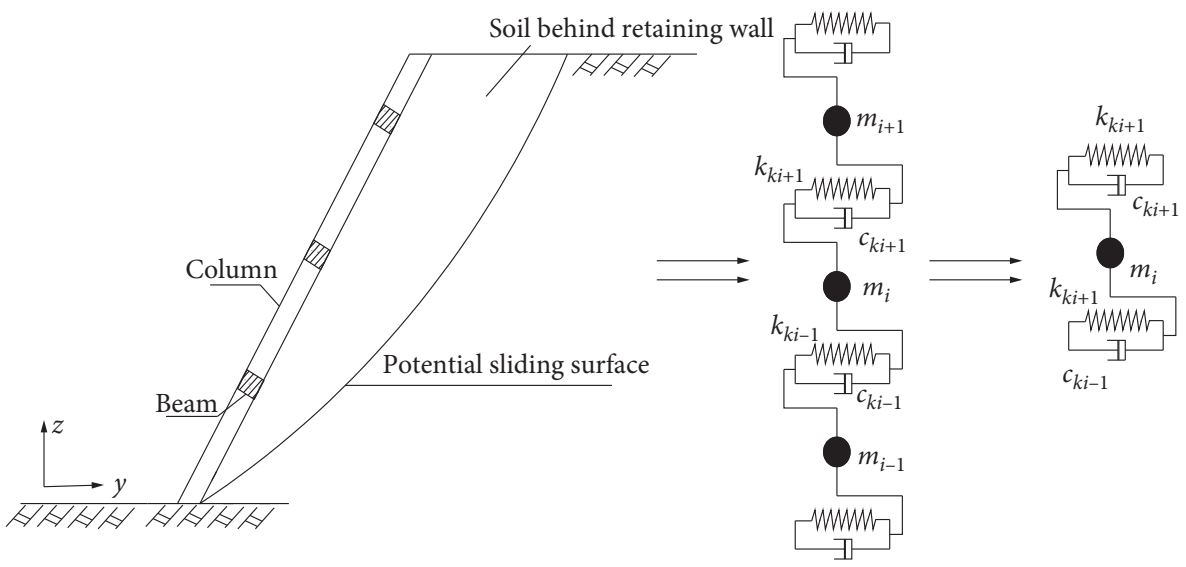

Figure 7: Model of frame structure.

(b) Without considering the torsional effect of beams and columns, the cross beams and columns are decomposed into independent continuous beams. Considering that the beam is an auxiliary bearing member, it only has the function of spatial coordination and is replaced by a spring in the frame. In order to simplify the model, it is not considered in the analysis. Therefore, it only takes columns as the research object in this case.

(c) Considering the interaction of soil-spring, the column is regarded as an elastic foundation beam.

(d) Considering the influence of frame on soil, the effect of frame structure on soil is considered as a parallel coupling of linear spring and linear damper. $k_{k i-1}$ and $k_{k i+1}$ are the frame spring stiffness, and $c_{k i-1}$ and $c_{k i+1}$ are the damping coefficients.

2.2. Establishment of the Prestressed Anchor. Thinking over the coupling effect of creep soil and anchors, the model of prestressed anchor is established as shown in Figure 8. When establishing the calculation model of the prestressed anchor, the following assumptions are made $[7,8]$ :

(a) The free section of the prestressed anchor is regarded as a linear spring, with a spring stiffness coefficient of $k_{f}$. The anchoring section of the prestressed anchor is a linear elastic body with continuous mass distribution.

(b) Considering the creep characteristics of soil, the Generalized Kelvin model is adopted to simulate the creep soil. Here, $E_{l}, E_{h}$, and $c_{l}$ are the parameters considering the coupling effect between the creep soil and the anchor.

(c) The anchoring section of the prestressed anchor is a linear elastic body with continuous mass distribution. In the analysis, the coupling effect of creep soil and anchors is considered and an equivalent spring body is used to simulate the anchoring section of anchor, with the spring stiffness of $E_{a}$.

(d) The restraint of soil on the end of the anchor is represented by a fixed support. 


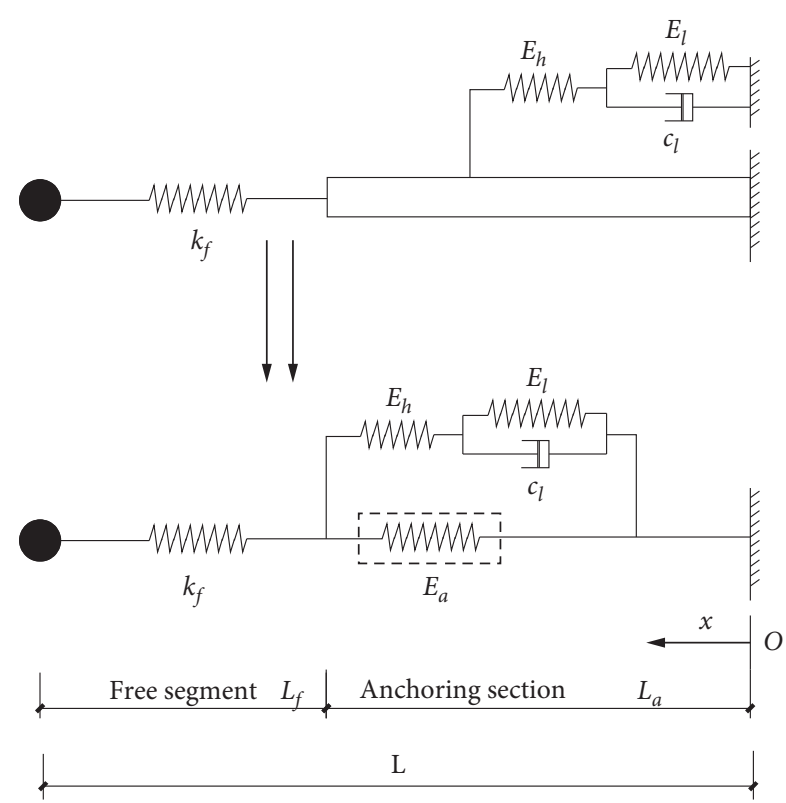

FIGURE 8: Model of the prestressed anchor.

In the model, the total length of the anchor is $L$, of which the free section is $L_{f}$ and the anchoring section is $L_{a}$. In the analysis, the coupling between the equivalent spring body and the Generalized Kelvin body is considered by taking the microelement body from the anchoring section of the anchor.

\section{Establishment and Solution of Dynamic Control Equation}

3.1. Seismic Excitation considering the Effect of Slope Height. Generally, the seismic excitation shows random ground motion. In order to facilitate calculation, the random ground motion can be adjusted to regular simple harmonics according to the principle of acceleration equivalence [22]:

$$
u_{g}^{\prime}(t)=0.1(M-1) u_{g \max }^{\prime} \sin \frac{2 \pi}{T_{g}} t
$$

where $u_{g \text { max }}^{\prime}$ is the peak value of earthquake acceleration; $T_{g}$ is the period of earthquake motion; and $M$ is the magnitude. The adjusted ground motion can be analyzed according to simple harmonics.

The seismic excitation $u_{g}^{\prime}(t)$ is vertically incident from the bottom of the slope and will puce reflection and refraction in the process of propagating through soil to the slope surface and anchor interface. Various types of waves overlap each other in the slope body to form a complex seismic wave field, resulting in different motion laws of different particles in the slope. Measured by the seismic acceleration $u_{g}(t)$, the difference between the particles is reflected in the magnitude of the amplitude and the time difference of the arrival of the first wave, but the vibration frequency is consistent.

For this reason, the coefficient of slope height effect (the anchoring height amplification coefficient $\psi\left(h_{i}\right)$, the acceleration lag delay coefficient $\left.t_{0}\left(h_{i}\right)\right)$ is induced, and the seismic acceleration $u_{g}(t)$ corresponding to different anchoring heights $h_{i}$ of the slope can refer to the general dynamic response law of the slope [23].

When $\bar{H}<\bar{H}_{\text {thre }}$,

$$
\left\{\begin{array}{l}
u_{g}(t)=\left\{\begin{array}{cc}
0 & {\left[0 \leq t<t_{0}\left(h_{i}\right)\right]} \\
\psi\left(h_{i}\right) u_{g}^{\prime}\left[t-t_{0}\left(h_{i}\right)\right] & {\left[t \geq t_{0}\left(h_{i}\right)\right]}
\end{array}\right\}, \\
\psi\left(h_{i}\right)=1+\frac{h_{i}}{H}\left(\alpha_{\max }-1\right) .
\end{array}\right.
$$

When $\bar{H} \geq \bar{H}_{\text {thre }}$,

$$
\left\{\begin{array}{l}
u_{g}(t)=\left\{\begin{array}{cc}
0 & {\left[0 \leq t<t_{0}\left(h_{i}\right)\right]} \\
\psi\left(h_{i}\right) u_{g}^{\prime}\left[t-t_{0}\left(h_{i}\right)\right] & {\left[t \geq t_{0}\left(h_{i}\right)\right]}
\end{array}\right\}, \\
\psi\left(h_{i}\right)=\left\{\begin{array}{cc}
1 & \left(h_{i}<\bar{H}-\bar{H}_{\text {thre }}\right) \\
1+\frac{\left(\alpha_{\text {max }}-1\right)\left(h_{i}-\bar{H}+\bar{H}_{\text {thre }}\right)}{\bar{H}_{\text {thre }}} & \left(\bar{H} \geq h_{i}>\bar{H}-\bar{H}_{\text {thre }}\right)
\end{array}\right\},
\end{array}\right.
$$

where $\bar{H}_{\text {thre }}$ is the critical height, $\bar{H}_{\text {thre }}=0.2 T g \sqrt{G_{s} / \rho} ; t_{0}\left(h_{i}\right)$ is the acceleration lag delay coefficient, $t_{0}\left(h_{i}\right)=h_{i} \sqrt{\rho / G_{s}}$; $\alpha_{\max }$ is the dynamic amplification factor, 3.0, 2.5, and 2.0 are taken when the seismic fortification intensity is 7,8 , and 9 degrees, respectively; $G_{s}$ and $\rho$ are the shear modulus and density of the slope soil respectively; and $h_{i}$ is the vertical distance between the anchor position and the slope toe.

3.2. Establishment of Dynamic Control Equation. Under the action of earthquake, the calculation model of the prestressed anchors with frame structure is shown in Figure 5. In order to facilitate the dynamic solution, it is decomposed into the model unit 1 and the model unit 2 (Figure 9), where the model unit 1 represents the frame structure-prestressed anchor system. The model element 2 is a microelement taken from the anchoring section of the anchor and represents the prestressed anchor-soil system.

According to Figure 9(a), the following formula is obtained:

$$
\begin{aligned}
& m \frac{\partial^{2} u_{k}}{\partial t^{2}}+\left(c_{k i+1}+c_{k i-1}\right) \frac{\partial u_{k}}{\partial t}+\left(k_{k i+1}+k_{k i-1}\right) u_{1} \\
& =-F_{e}(t)-F_{p}, \\
& F_{e}(t)=m \frac{\partial^{2} u_{g}}{\partial t^{2}} \cos \alpha, \\
& F_{p}=k_{f} u_{1},
\end{aligned}
$$

where $F_{p}$ is the prestress of the anchor; $F_{e}(t)$ is the seismic load; $u_{1}$ is the displacement of the free section of the anchor, which is equal to the displacement of the frame $u_{k}$ according 


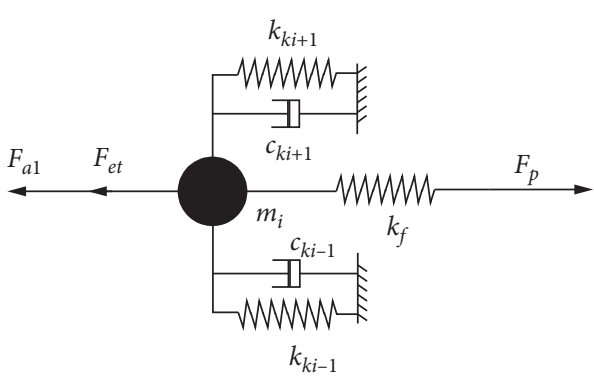

(a)

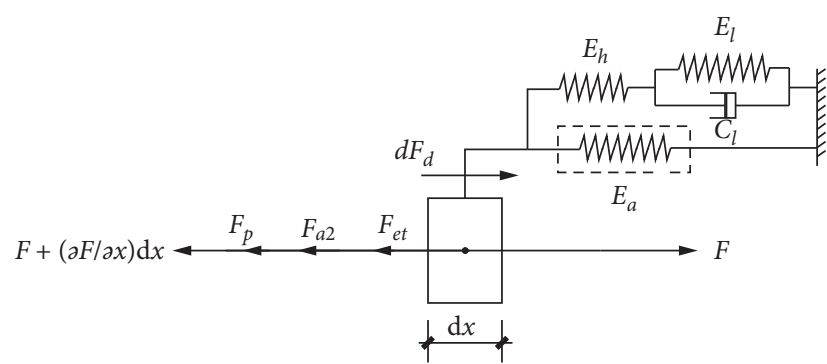

(b)

Figure 9: The calculation unit of the model. (a) Model unit 1. (b) Model unit 2.

to the assumption, that is $u_{1}=u_{k}$; and $F_{a 1}$ is the concentrated mass inertial force, $F_{a 1}=m\left(\partial^{2} u_{k} / \partial t^{2}\right)$. To simplify the analysis process, let

$$
\left\{\begin{array}{l}
c_{k}=c_{k i+1}+c_{k i-1} \\
k_{k}=k_{k i+1}+k_{k i-1}
\end{array}\right.
$$

Among them, $c_{k}$ and $k_{k}$ are the damping coefficient and spring stiffness of the frame, respectively. Substituting formulas (6) to (8) into formula (5), the solution is set as follows:

$$
m \frac{\partial^{2} u_{1}}{\partial t^{2}}+c_{k} \frac{\partial u_{1}}{\partial t}+\left(k_{k}-k_{f}\right) u_{1}=-m \frac{\partial^{2} u_{g}}{\partial t^{2}} \cos \alpha .
$$

Taking the microelement from the anchoring section of the anchor, as shown in Figure 9(b), the following formula is obtained:

$$
F+\frac{\partial F}{\partial x}+F_{p}+F_{a 2}+F_{e t}=d F_{d}+F
$$

where $F$ is the microelement internal force of anchoring section, $F=A_{s} E_{a}\left(\partial u_{2} / \partial x\right) ; E_{a}$ and $A_{s}$ are the elastic modulus and cross-sectional area of the anchoring section, respectively; the relation between them is $E_{a}=k_{a} / A_{s} ; u_{2}$ is the relative displacement of anchoring section; $F_{a 2}$ is the centralized mass inertia force in anchoring section, $F_{a 2}=\rho A_{s}\left(\partial^{2} u_{2} / \partial t^{2}\right) \mathrm{d} x$; and $F_{e}(t)$ is the earthquake load, $F_{e}(t)=\rho A_{s}\left(\partial^{2} u_{g} / \partial t^{2}\right) \mathrm{d} x \cos \alpha$.

It can be concluded that

$$
\begin{aligned}
A_{s} & E_{a} \frac{\partial^{2} u_{2}}{\partial x^{2}} \mathrm{~d} x+k_{f} u_{1}+\rho A_{s} \frac{\partial^{2} u_{2}}{\partial t^{2}} \mathrm{~d} x-d F_{d} \\
& =-\rho A_{s} \frac{\partial^{2} u_{g}}{\partial t^{2}} \mathrm{~d} x \cos \alpha,
\end{aligned}
$$

where $d F_{d}$ is the axial force increment of the microelement in the anchoring section. The calculation method is as follows.

As shown in Figure 10, considering the relationship between the anchor and the soil mass, the established coupled calculation model is composed of two parts: the first part is the General Kelvin model, which is used to simulate the creep soil; the second part is an equivalent spring body, which is used to simulate the anchor. According to the principle of series-parallel connection of components:

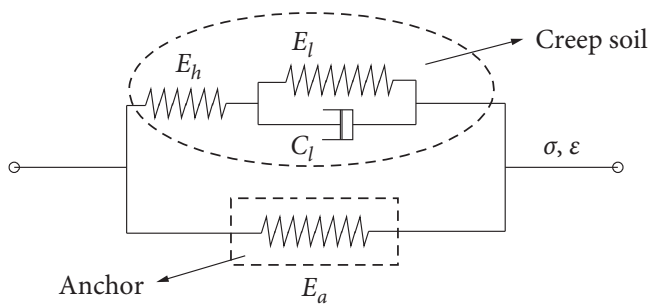

FIGURE 10: Coupled model of anchor-creep medium.

Series connection: $\sigma=\sigma_{1}=\sigma_{2}=\cdots, \varepsilon=\varepsilon_{1}+\varepsilon_{2}+\cdots$;

Parallel connection: $\sigma=\sigma_{1}+\sigma_{2}+\cdots, \varepsilon=\varepsilon_{1}=\varepsilon_{2}=\cdots$;

The constitutive equation of Generalized Kelvin style is obtained:

$$
\frac{c_{l}}{E_{h}} \dot{\sigma}+\left(1+\frac{E_{l}}{E_{h}}\right) \sigma=c_{l} \dot{\varepsilon}+E_{l} \varepsilon .
$$

That is,

$$
\dot{\sigma}+\frac{E_{l}+E_{h}}{c_{l}} \sigma=\frac{E_{h} c_{l} \dot{\varepsilon}+E_{h} E_{l} \varepsilon}{c_{l}} .
$$

The solution is as follows:

$$
\sigma=C e^{-\left(\left(E_{h}+E_{l}\right) / c_{l}\right) t}+\frac{E_{h} c_{l} \dot{\varepsilon}+E_{h} E_{l} \varepsilon}{E_{l}+E_{h}} .
$$

When $t=0$ and $\sigma=0$, there are

$$
\begin{aligned}
C & =-\frac{E_{h} c_{l} \dot{\varepsilon}+E_{h} E_{l} \varepsilon}{E_{l}+E_{h}}, \\
\sigma & =-\frac{E_{h} c_{l} \dot{\varepsilon}+E_{h} E_{l} \varepsilon}{E_{l}+E_{h}} e^{-\left(\left(k_{h}+k_{l}\right) / c_{l}\right) t}+\frac{E_{h} c_{l} \dot{\varepsilon}+E_{h} E_{l} \varepsilon}{E_{l}+E_{h}} .
\end{aligned}
$$

Formula (16) takes into account the coupling of creep soil and prestressed anchors. When the initial strain of anchorage section is $\varepsilon\left(\varepsilon=\partial u_{2} / \partial x\right)$, the axial force increment of microelement in the anchorage section is as follows:

$$
\begin{aligned}
d F_{d} & =\sigma A_{s} \mathrm{~d} x=(1-P)\left(\frac{E_{h} c_{l} A_{s}}{E_{l}+E_{h}} \frac{\partial^{2} u_{2}}{\partial x^{2}}+\frac{E_{h} E_{l} A_{s}}{E_{l}+E_{h}} \frac{\partial u_{2}}{\partial x}\right) \mathrm{d} x \\
P & =e^{-\left(\left(E_{h}+E_{l}\right) / c_{l}\right) t} .
\end{aligned}
$$


Substituting formula (17) into formula (11), the following formula can be obtained:

$$
\frac{E_{a}}{\rho} \frac{\partial^{2} u_{2}}{\partial x^{2}}+\frac{k_{f}}{\rho A_{s}} \frac{1}{\Delta x} u_{1}+\frac{\partial^{2} u_{2}}{\partial t^{2}}-\left[\frac{(1-P)}{\rho} \frac{E_{h} c_{l}}{E_{l}+E_{h}} \frac{\partial^{2} u_{2}}{\partial x^{2}}+\frac{(1-P)}{\rho} \frac{E_{h} E_{l}}{E_{l}+E_{h}} \frac{\partial u_{2}}{\partial x}\right]=-\frac{\partial^{2} u_{g}}{\partial t^{2}} \cos \alpha .
$$

Let $\quad A=\sqrt{\left(E_{a} / \rho\right)-((1-P) / \rho)\left(E_{h} c_{l} /\left(E_{l}+E_{h}\right)\right)}, \quad B=$ $k_{f} / \rho A_{s}$, and $C=((1-P) / \rho)\left(E_{h} E_{l} /\left(E_{l}+E_{h}\right)\right)$.

Then, formula (19) is transformed into

$A^{2} \frac{\partial^{2} u_{2}}{\partial x^{2}}+\frac{\partial^{2} u_{2}}{\partial t^{2}}+B \frac{1}{\Delta x} u_{1}-C \frac{\partial u_{2}}{\partial x}=-\frac{\partial^{2} u_{g}}{\partial t^{2}} \cos \alpha$.

Initial conditions are as follows:

$$
\begin{array}{ll}
u_{1}(0, t)=0, & L_{a} \leq x \leq L, \\
u_{2}(0, t)=0, & 0 \leq x \leq L_{a} .
\end{array}
$$

Boundary conditions are as follows:

$$
\begin{gathered}
u_{1}(0, t)=0, \\
\left.\frac{\partial u_{1}(x, t)}{\partial x}\right|_{x=L}=\left.\frac{\partial u_{k}(x, t)}{\partial x}\right|_{x=L} .
\end{gathered}
$$

Displacement coordination condition is as follows:

$$
u_{1}\left(L_{a}, t\right)=u_{2}\left(L_{a}, t\right) .
$$

3.3. Dynamic Response Solution. According to formulas (2)-(4), when $0 \leq t<t_{0}\left(h_{i}\right)$, there is no seismic acceleration response. When $t \geq t_{0}\left(h_{i}\right)$, the earthquake acceleration is $u_{g}=\psi\left(h_{i}\right) u_{g}^{\prime} \sin \omega\left[t-t_{0}\left(h_{i}\right)\right]$. To simplify the calculation, let $u_{g}=\psi\left(h_{i}\right) U_{g} e^{i \omega\left[t-t_{0}\left(h_{i}\right)\right]}$. Here, $U_{g}$ is the simple harmonic motion amplitude. The complex number method is used to solve the problem, and the imaginary part after solution is actual seismic excitation response [24]. The seismic excitation is substituted into formula (9) to obtain

$$
\begin{aligned}
& m \frac{\partial^{2} u_{1}}{\partial t^{2}}+c_{k} \frac{\partial u_{1}}{\partial t}+\left(k_{k}-k_{f}\right) u_{1} \\
& =m \cos \alpha \psi\left(h_{i}\right) U_{g} \omega^{2} e^{i \omega\left[t-t_{0}\left(h_{i}\right)\right]} .
\end{aligned}
$$

Assuming that the solution of the formula is $u_{1}(x, t)=\psi\left(h_{i}\right) U_{1} e^{i \omega\left[t-t_{0}\left(h_{i}\right)\right]}$; substitute it into formula (25) to obtain

$$
-m \omega^{2} U_{1}+i \omega c_{k} U_{1}+\left(k_{k}-k_{f}\right) U_{1}=m \omega^{2} U_{g} \cos \alpha .
$$

Solve

$$
\begin{gathered}
U_{1}=\frac{m \omega^{2} U_{g} \cos \alpha}{i \omega c_{k}-m \omega^{2}+k_{k}-k_{f}}, \\
u_{1}(x, t)=\frac{m \omega^{2} U_{g} \cos \alpha}{i \omega c_{k}-m \omega^{2}+k_{k}-k_{f}} \psi\left(h_{i}\right) e^{i \omega\left[t-t_{0}\left(h_{i}\right)\right]} .
\end{gathered}
$$

Similarly, the seismic excitation $u_{g}=\psi\left(h_{i}\right) u_{g}^{\prime} \sin \omega[t-$ $t_{0}\left(h_{i}\right)$ ] is substituted into formula (20) and $u_{1}$ is considered as known. Let $u_{2}(x, t)=\psi\left(h_{i}\right) U_{2} e^{i \omega\left[t-t_{0}\left(h_{i}\right)\right]}$ be the solution of formula (20); then, it is transformed into

$$
A^{2} \frac{\mathrm{d}^{2} U_{2}}{\mathrm{~d} x^{2}}-\omega^{2} U_{2}-i C \omega U_{2}=\omega^{2} U_{g} \cos \alpha-\frac{B u_{1} / \Delta x}{\psi\left(h_{i}\right) e^{i \omega\left[t-t_{0}\left(h_{i}\right)\right]}} .
$$

That is,

$$
\frac{\mathrm{d}^{2} U_{2}}{\mathrm{~d} x^{2}}-\left(\omega^{2}+i C \omega\right) U_{2}=\frac{\omega^{2} U_{g} \cos \alpha-\left(\left(B u_{1} / \Delta x\right) / \psi\left(h_{i}\right) e^{i \omega\left[t-t_{0}\left(h_{i}\right)\right]}\right)}{A^{2}} .
$$

Let $D_{1}=-\left(\omega^{2}+i C \omega\right), D_{2}=\left(\omega^{2} U_{g} \cos \alpha-\left(\left(B u_{1} / \Delta x\right) /\right.\right.$ $\left.\left.\psi\left(h_{i}\right) e^{i \omega\left[t-t_{0}\left(h_{i}\right)\right]}\right)\right) / A^{2}$. Then, the formula becomes

$$
\frac{\mathrm{d}^{2} U_{2}}{\mathrm{~d} x^{2}}+D_{1} U_{2}=D_{2}
$$

The solution of formula (30) is as follows:

$$
U_{2}(x)=C_{1} \cos \sqrt{D_{1}} x+C_{2} \sin \sqrt{D_{1}} x+\frac{D_{2}}{D_{1}} .
$$

The final solution of the displacement of the anchorage section is

$$
\begin{aligned}
u_{2}(x, t)= & \left(C_{1} \cos \sqrt{D_{1}} x+C_{2} \sin \sqrt{D_{1}} x+\frac{D_{2}}{D_{1}}\right) \\
& \cdot \psi\left(h_{i}\right) e^{i \omega\left[t-t_{0}\left(h_{i}\right)\right]},
\end{aligned}
$$

where $C_{1}$ and $C_{2}$ are determined by boundary conditions and displacement coordination conditions; they are 
substituted into formulae (22) and (24), respectively, to obtain the solution as follows:

$$
\begin{aligned}
C_{1} & =-\frac{D_{2}}{D_{1}}, \\
C_{2} & =\frac{\left(\left(m \omega^{2} U_{g} \cos \alpha\right) /\left(i \omega c_{k}-m \omega^{2}+k_{k}-k_{f}\right)\right)-\left(D_{2} / D_{1}\right)\left(1-\cos \sqrt{D_{1}} L_{a}\right)}{\sin \sqrt{D_{1}} L_{a}} .
\end{aligned}
$$

For specific $h_{i}, \psi\left(h_{i}\right)$ and $t_{0}\left(h_{i}\right)$ are considered as constants. In order to simplify the problem, the effect of acceleration delay can be neglected. That is, $t_{0}\left(h_{i}\right)=0$. It is considered that the vibration of each particle is synchronous, so that the calculation results are larger and safer, which also conforms to the design concept. The acceleration response can also be obtained from formula (32):

$$
\begin{aligned}
a_{2}(x, t)= & -\left(C_{1} \cos \sqrt{D_{1}} x+C_{2} \sin \sqrt{D_{1}} x+\frac{D_{2}}{D_{1}}\right) \omega^{2} \\
& \cdot \psi\left(h_{i}\right) e^{i \omega\left[t-t_{0}\left(h_{i}\right)\right]} .
\end{aligned}
$$

Let $\overline{u_{1}}(x, t)$ be the imaginary part of $u_{1}(x, t)$, and let $\overline{u_{2}}(x, t)$ be the imaginary part of $u_{2}(x, t)$. The prestress increment response of the free section obtained as follows:

$$
F_{p}=k_{f} \overline{u_{1}}(x, t)
$$

The axial force incremental response of anchoring section is

$$
F_{d}=(1-P)\left(\frac{E_{h} c_{l} A_{s}}{E_{l}+E_{h}} \frac{\partial^{2} \overline{u_{2}}}{\partial x^{2}}+\frac{E_{h} E_{l} A_{s}}{E_{l}+E_{h}} \frac{\partial \overline{u_{2}}}{\partial x}\right) .
$$

\section{Engineering Examples and Verification}

4.1. Project Overview. A slope in Lanzhou Citizen in Gansu Province, China, with a slope height of $12.0 \mathrm{~m}$ is considered, the soil is loess, and the soil parameters are shown in Table 1. The angle between the slope and the horizontal plane is 80 degrees, the seismic fortification intensity is 8 degrees, and the ground motion acceleration peak is $0.3 \mathrm{~g}$.

Through scheme optimization, the slope is supported by prestressed anchors with frame structure. Table 2 shows the design results. The cross-sectional dimensions of frame beam and column are $300 \mathrm{~mm} \times 300 \mathrm{~mm}$, and the thickness of retaining plate is $150 \mathrm{~mm}$. The design profile is shown in Figure 11.

4.2. Seismic Response. Calculation parameters [7, 8, 25] are as follows:

(a) The seismic excitation input is a horizontal sine wave with a seismic frequency of $2 \mathrm{~Hz}$ and an acceleration with a peak of $0.30 \mathrm{~g}$. (b) The elastic modulus of the anchoring section is $E_{a}=8 \times 10^{9} \mathrm{~N} / \mathrm{m}$. The elastic modulus of the anchor is $E=2.6 \mathrm{GPa}$.

(c) Creep parameters of soil are $E_{h}=9.3 \mathrm{MPa}$, $E_{l}=7.7 \mathrm{MPa}$, and $c_{l}=8160 \mathrm{kN} \cdot \mathrm{s} / \mathrm{m}$. The Poisson's ratio of soil is $\mu=0.3$. The shear modulus of soil is $G_{s}=10.5 \mathrm{MPa}$.

The above method is used to analyze the ground motion response of slope. By calculation, $\bar{H}_{\text {thre }}=2.53 \mathrm{~m} . \psi\left(h_{i}\right)$ and $t_{0}\left(h_{i}\right)$ are calculated according to formula (4). In order to compare the effect of slope height conveniently, the dynamic responses of the first, third, and sixth rows of anchors are listed in this paper, the prestress increment response of free section under earthquake are given through formula (35) as shown in Figure 12. The axial force increment response of anchoring section obtained by formula (36) is shown in Figure 13.

Due to the elastic deformation of the free section of anchor, the prestress changes with time. As shown in Figure 12, the prestress increment is $22 \mathrm{kN}$ in the first row, $9.2 \mathrm{kN}$ in the third row, and $7.5 \mathrm{kN}$ in the sixth row. Then, the prestress of the anchor is $122 \mathrm{kN}$ in the first row, $109.2 \mathrm{kN}$ in the third row, and $107.5 \mathrm{kN}$ in the sixth row, respectively. That is, the prestress of the anchor from the bottom of the slope to the top of the slope increases gradually along the direction of the slope height, with significant amplification effect at the top of the slope.

Considering the coupling effect of creep soil and prestressed anchors, the axial force of the anchoring section of the anchor has changed. Figure 13 shows the increment of the axial force at the connection between the free section and the anchorage section, which is $24.8 \mathrm{kN}$ in the first row, $12 \mathrm{kN}$ in the third row, and $3.3 \mathrm{kN}$ in the sixth row from the bottom of the slope to the top of the slope along the direction of the slope height. So, the axial forces at the connection between free section and anchorage section are $124.8 \mathrm{kN}$, $112 \mathrm{kN}$, and $103.3 \mathrm{kN}$, respectively. From Figures 12 and 13, it can be seen that the seismic response of each layer of anchors is different at the time when the first wave reaches the peak, which indicates that when considering the effect of slope height, the seismic response of slope body has amplitude difference and delay phenomenon, with significant amplification effect at the top of slope.

4.3. Test Verification. The results of the shaking table model test of the slope supported by frame anchors in reference 
TABLE 1: Soil parameters.

\begin{tabular}{lcccc}
\hline Statistical parameter & Unit weight $\gamma\left(\mathrm{kN} / \mathrm{m}^{3}\right)$ & Cohesion $c(\mathrm{kPa})$ & Friction angle $\varphi(\mathrm{deg})$ & Ultimate friction $q_{s}(\mathrm{kPa})$ \\
\hline Value & 16.4 & 18 & 25.0 & 50.0
\end{tabular}

TABLe 2: Design results of anchors.

\begin{tabular}{|c|c|c|c|c|c|c|c|}
\hline $\begin{array}{l}\text { Anchor } \\
\text { layer }\end{array}$ & $\begin{array}{l}\text { Horizontal } \\
\text { distance }(\mathrm{m})\end{array}$ & $\begin{array}{c}\text { Vertical } \\
\text { distance }(\mathrm{m})\end{array}$ & $\begin{array}{l}\text { Anchorage body } \\
\text { diameter }(\mathrm{mm})\end{array}$ & $\begin{array}{l}\text { Reinforcement } \\
\text { diameter }(\mathrm{mm})\end{array}$ & $\begin{array}{l}\text { Free segment } \\
\text { length }(\mathrm{m})\end{array}$ & $\begin{array}{c}\text { Anchorage } \\
\text { segment length } \\
(\mathrm{m})\end{array}$ & $\begin{array}{l}\text { Total length of } \\
\text { the anchor }(\mathrm{m})\end{array}$ \\
\hline 1 & 2.0 & 2.0 & 150 & 28 & 6 & 10 & 16 \\
\hline 2 & 2.0 & 2.0 & 150 & 28 & 5 & 10 & 15 \\
\hline 3 & 2.0 & 2.0 & 150 & 28 & 5 & 9 & 14 \\
\hline 4 & 2.0 & 2.0 & 150 & 28 & 4 & 8 & 12 \\
\hline 5 & 2.0 & 2.0 & 150 & 28 & 4 & 7 & 11 \\
\hline 6 & 2.0 & 2.0 & 150 & 28 & 4 & 5 & 9 \\
\hline
\end{tabular}

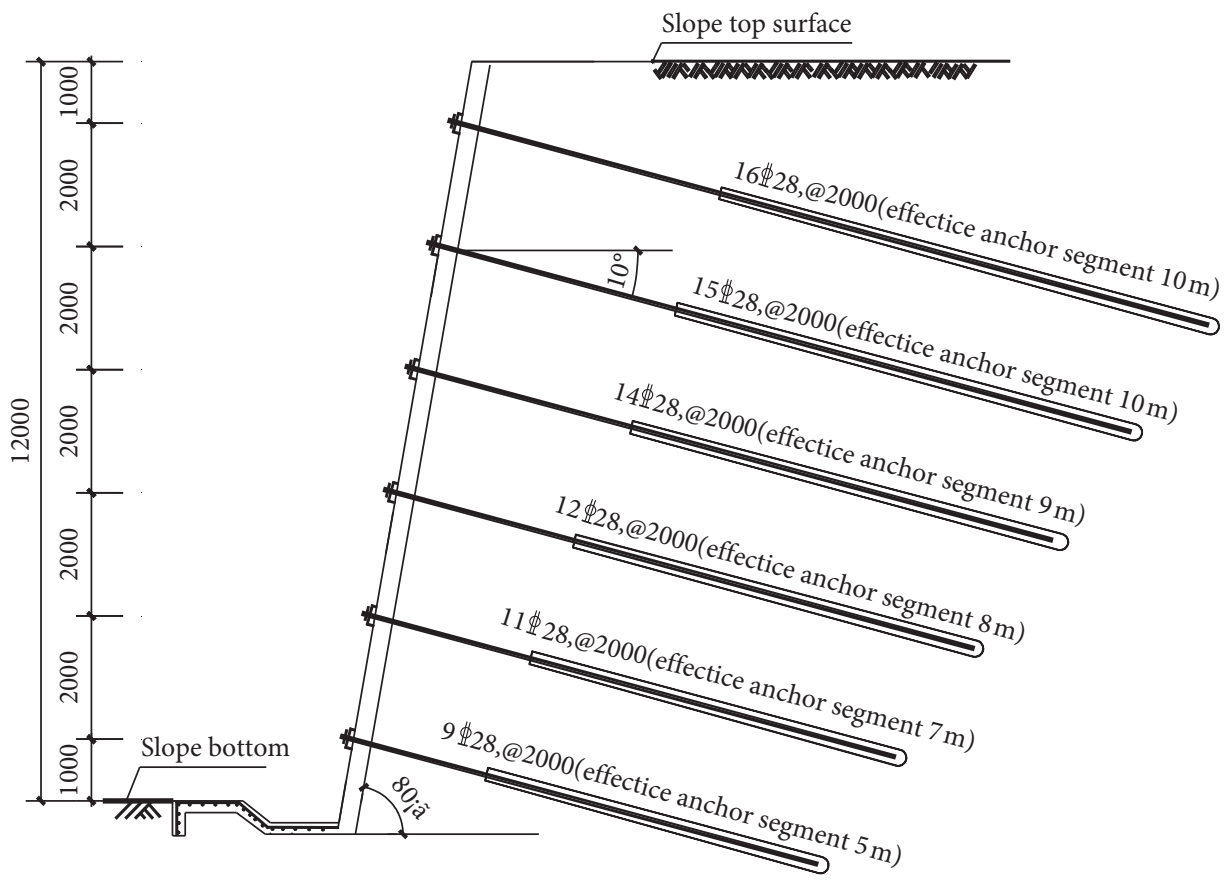

FIgURE 11: Slope support profile.

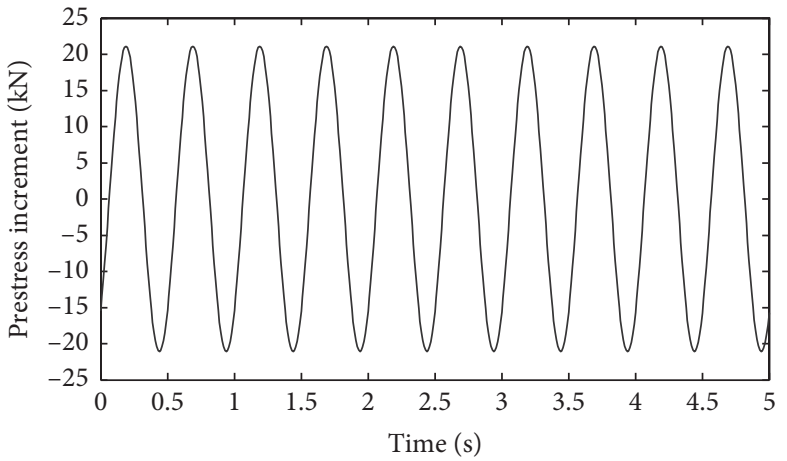

(a)

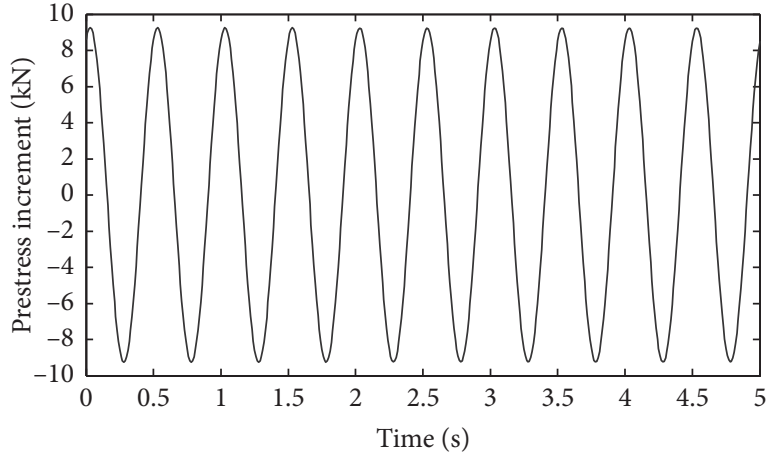

(b)

FIgURE 12: Continued. 


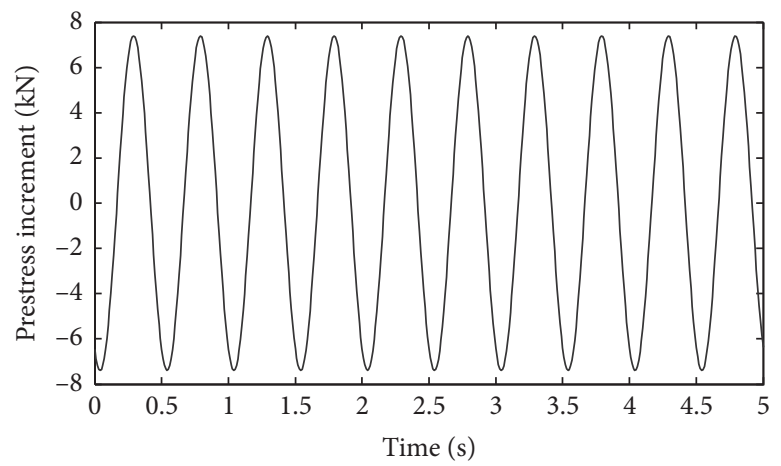

(c)

Figure 12: Prestress increment time histories. (a) The first row of anchors. (b) The third row of anchors. (c) The sixth row of anchors.

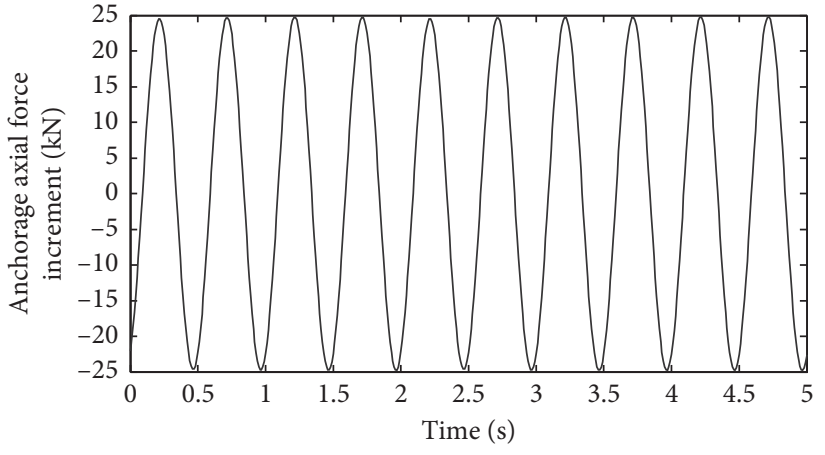

(a)

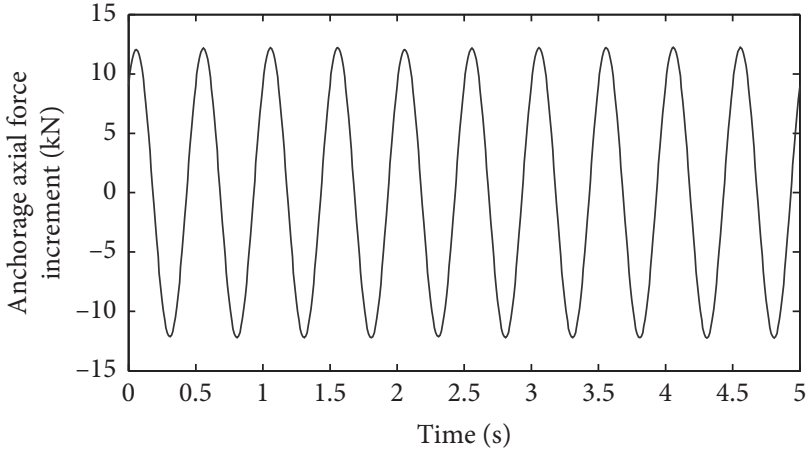

(b)

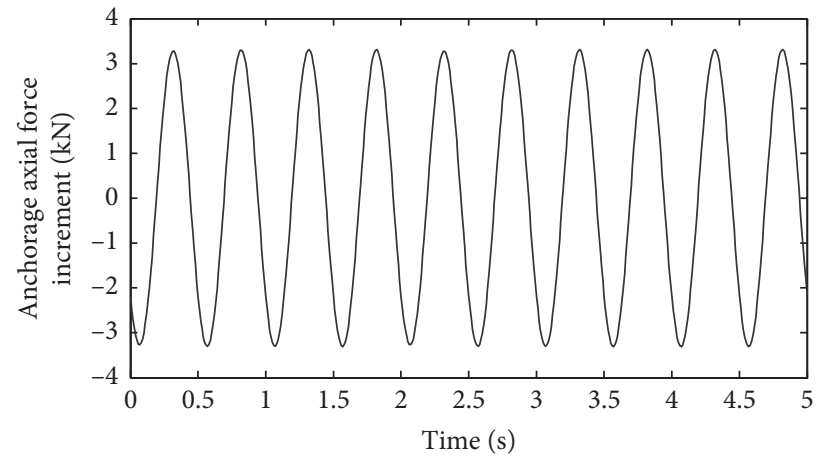

(c)

FIgURE 13: Anchorage axial force increment time histories. (a) The first row of anchors $(x=10 \mathrm{~m})$. (b) The third row of anchors $(x=9 \mathrm{~m})$. (c) The sixth row of anchors $(x=5 \mathrm{~m})$.

[26] are compared with this paper. The acceleration response is compared and analyzed here.

Figure 14 is the acceleration time-history curve of the first row of anchors and the sixth row of anchors calculated by the method in this paper (which is obtained by formula (34)), in which the peak acceleration of the first row is $5.1 \mathrm{~m} / \mathrm{s}^{2}$ and the peak acceleration of the sixth row is $3.2 \mathrm{~m} / \mathrm{s}^{2}$. The peak acceleration is enlarged to different degrees, especially at the top of the slope. Figure 15 shows the distribution of acceleration amplification factor along the slope height of slope supported by frame with prestressed anchors under earthquake (where $h$ is the height of measuring point and $H$ is the total height of slope). In the shaking table test, the seismic wave (in reference [26], the working condition of Lanzhou wave) is selected when the peak acceleration is $0.3 \mathrm{~g}$. It can be seen that the result of the shaking table test is close to the calculated value in this paper, and the amplification effect of the calculated value 


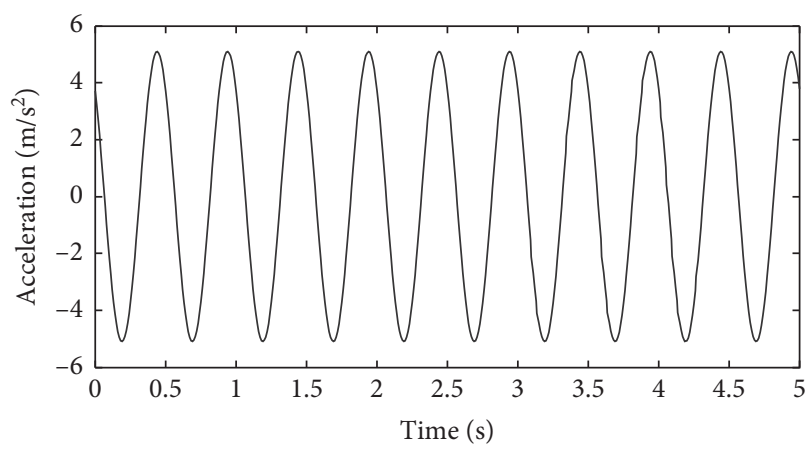

(a)

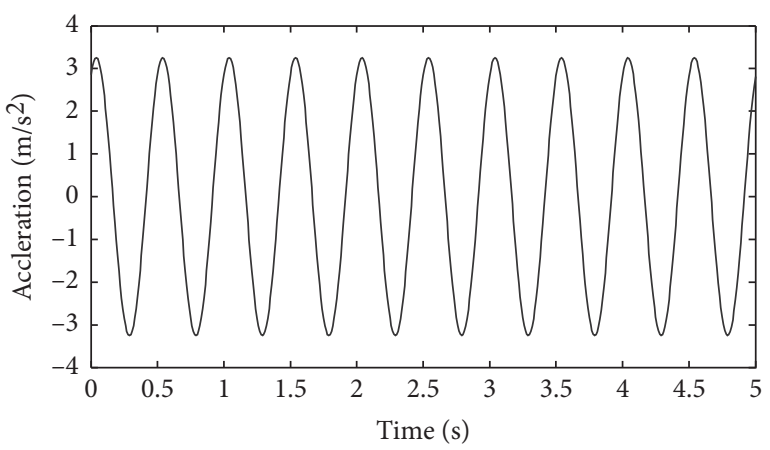

(b)

Figure 14: Acceleration time histories. (a) The first row of anchors. (b) The sixth row of anchors.

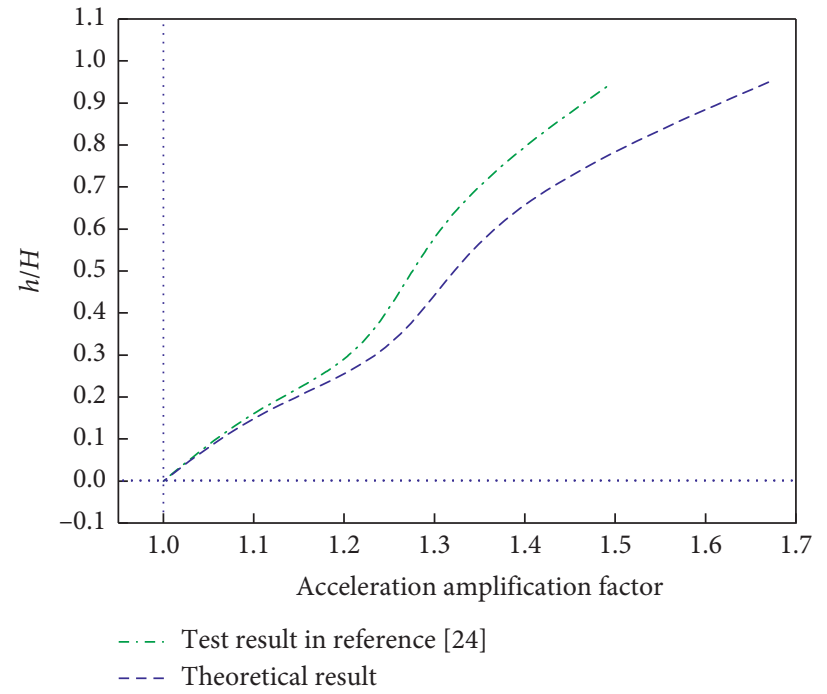

Figure 15: Acceleration amplification factor.

at the top of the slope is larger than the test value. In practical engineering, the support design based on the calculation method in this paper will be more conservative and safer.

4.4. Numerical Verification. According to the engineering example in Section 4.1, the finite element software PLAXIS $3 \mathrm{D}$ is used to carry out the numerical simulation of the slope supported by prestressed anchors with frame, in which the soil mass of the slope is loess, and the parameters of soil are the same as those in Table 1, and the structural parameters are shown in Table 3. The constitutive relation of the model soil was Coulomb-Moore elastic-plastic model, and the model size is $50 \mathrm{~m} \times 25 \mathrm{~m} \times 2 \mathrm{~m}$. The beam and column adopt beam unit, the free section of the anchor adopts point-to-point anchor unit, and the anchoring section adopts the embedded pile unit. Rayleigh damping is adopted for damping. The free section is in rigid contact with the anchoring section. The input seismic wave is shown in Figure 16. The model is built as shown in Figure 17.

The axial force of the anchor is analyzed. The distribution of the axial force is given in Figure 18 and Table 4. It can be seen that the distribution of the axial force is basically the same. The axial force of the anchorage section decreases gradually along the length of the anchor; that is, from the connection between the free section and the anchorage section to the end of the anchor, the axial force becomes smaller and smaller. The peak values of the first row of anchor are $122 \mathrm{kN}$ and $115.27 \mathrm{kN}$, respectively, and the sixth row of anchor are $107.5 \mathrm{kN}$ and $97.48 \mathrm{kN}$, respectively.

Because the effect of frame on soil is considered in this paper, the calculated axial force of anchor in free section is larger than that of numerical simulation. From Table 4, it can be seen that the numerical simulation results are very close to the calculated values in this paper. There are some errors between the numerical simulation results and the calculation results in this paper, which are mainly caused by the 
TABLE 3: Material parameters of supporting structures.

\begin{tabular}{|c|c|c|c|c|}
\hline Parameter & Beam and column & $\begin{array}{l}\text { Free segment of the } \\
\text { anchor }\end{array}$ & $\begin{array}{l}\text { Anchoring section of the } \\
\text { anchor }\end{array}$ & Retaining plate \\
\hline$E\left(\mathrm{kN} / \mathrm{m}^{2}\right)$ & $2.5 \times 10^{7}$ & $6.5 \times 10^{4}$ & $3.0 \times 10^{7}$ & $1.495 \times 10^{6}$ \\
\hline$\gamma\left(\mathrm{kN} / \mathrm{m}^{3}\right)$ & 25 & - & 22 & 22 \\
\hline Beam type & Predefined & - & Predefined & - \\
\hline Predefined beam type & $\begin{array}{l}\text { Massive rectangular } \\
\text { beam }\end{array}$ & - & Massive circular beam & - \\
\hline Height (m) & 0.8 & - & Diameter $=0.15$ & Thickness $=0.15$ \\
\hline Width (m) & 0.8 & - & & \\
\hline Side friction & - & - & Linear elastic & - \\
\hline Ultimate side friction of pile top & - & - & $200 \mathrm{kN} / \mathrm{m}$ & - \\
\hline $\begin{array}{l}\text { Ultimate side friction of pile } \\
\text { bottom }\end{array}$ & - & - & $0 \mathrm{kN} / \mathrm{m}$ & - \\
\hline $\begin{array}{l}\text { Limit reaction force of pile } \\
\text { bottom }\end{array}$ & - & - & $0 \mathrm{kN}$ & - \\
\hline
\end{tabular}

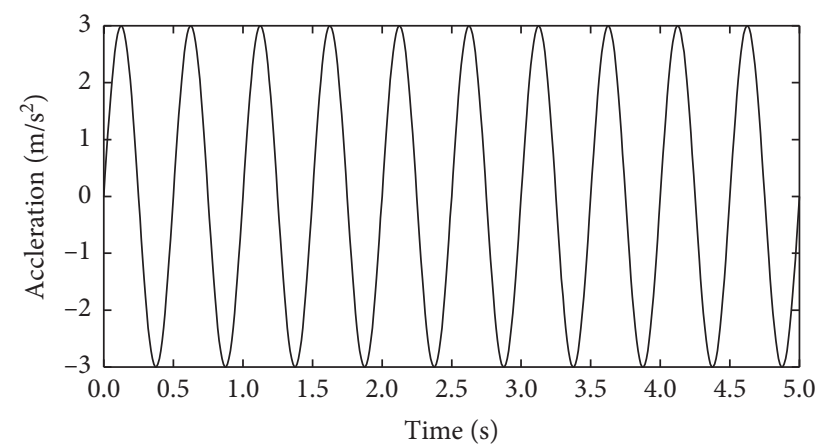

FIGURE 16: The input seismic wave.

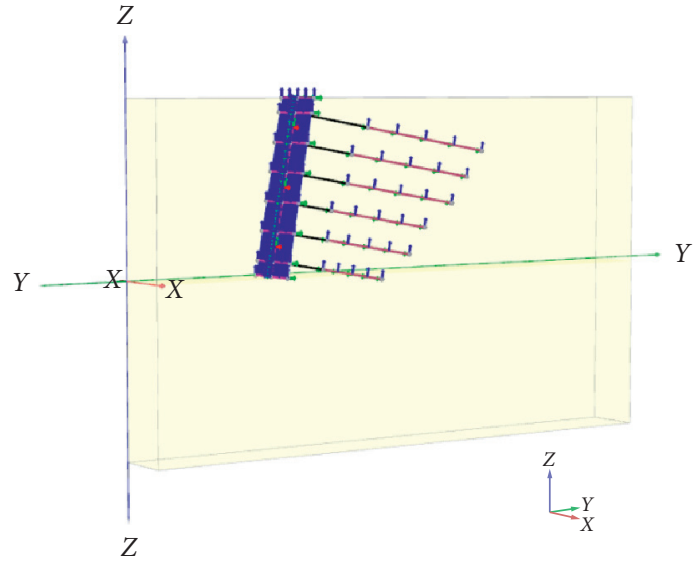

(a)

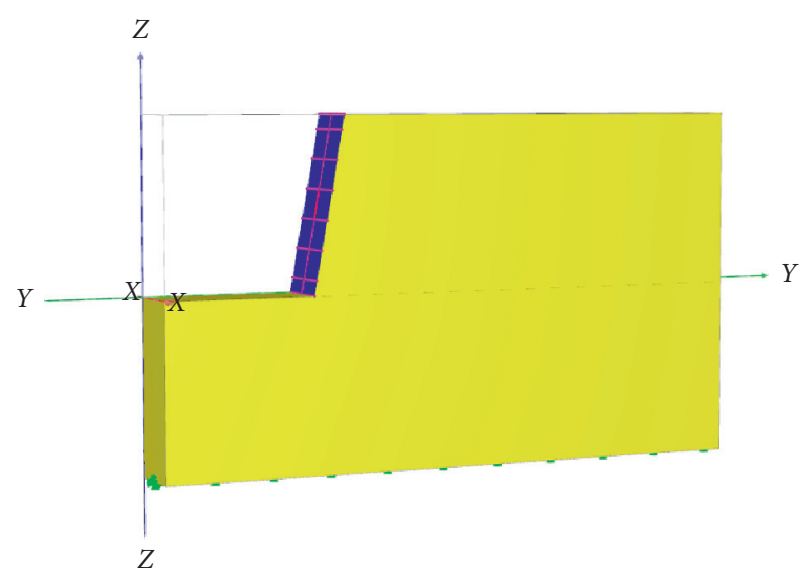

(b)

FIgURE 17: Finite element model. (a) The model of prestressed anchors with frame structure. (b) Established model.

simplification of the theoretical calculation model and the influence of the selection of materials and simulation elements in the finite element numerical model.

Figure 19 shows the acceleration time-history curves of the first and sixth rows of anchors. It can be seen that the acceleration peak values of the first row and the sixth row are $5.34 \mathrm{~m} / \mathrm{s}^{2}$ and $3.57 \mathrm{~m} / \mathrm{s}^{2}$, respectively, while the acceleration peak values calculated in this paper are $5.1 \mathrm{~m} / \mathrm{s}^{2}$ and $3.2 \mathrm{~m} / \mathrm{s}^{2}$, respectively (Figure 16 ). The results are very close, and the difference of frequency and amplitude is mainly caused by the simplification process of the calculation method in this paper, which has little influence on the results. It shows that the method proposed in this paper is reasonable and feasible. 


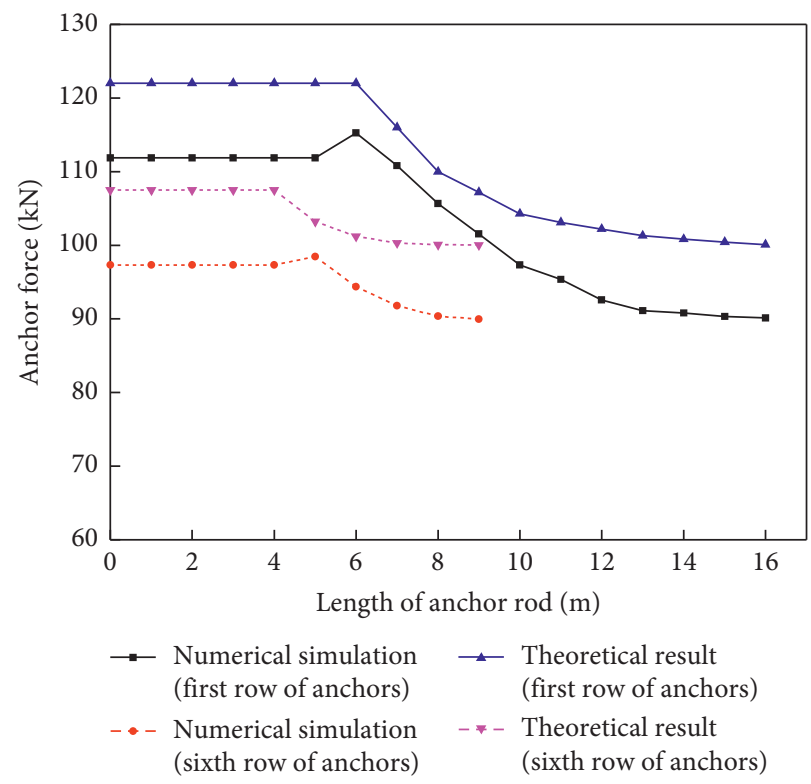

Figure 18: Distribution of axial force.

TABLE 4: Peak axial force for anchors.

\begin{tabular}{lcccccc}
\hline Number of anchor rows & 1 & 2 & 3 & 4 & 5 & 5 \\
\hline Numerical result $(\mathrm{kN})$ & 115.27 & 100.69 & 99.68 & 97.56 & 97.52 \\
Theoretical result $(\mathrm{kN})$ & 122 & 117 & 112 & 110 & 107.5 & 107.5 \\
\hline
\end{tabular}

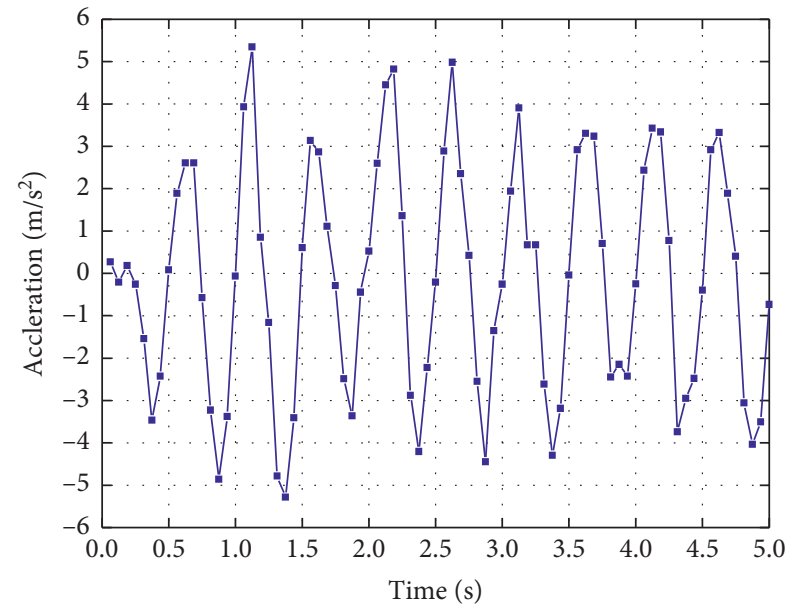

(a)

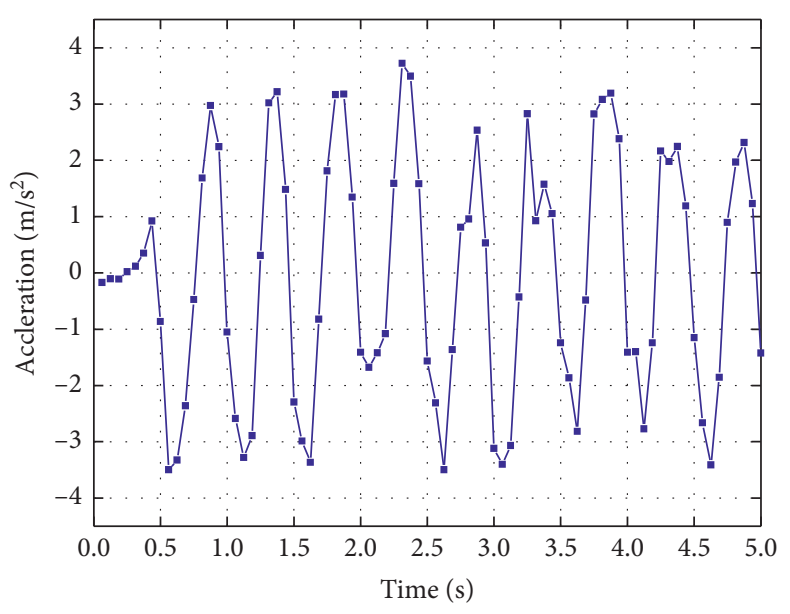

(b)

Figure 19: Acceleration time histories. (a) The first row of anchors. (b) The sixth row of anchors.

\section{Conclusions}

By establishing and solving the dynamic calculation model of the supporting structure of prestressed anchors with frame structure, the following conclusions are obtained:

(1) Considering the coupling effect between creep soil and prestressed anchors, the equivalent mass-spring model is applied to the dynamic calculation model of the supporting structure of prestressed anchors with frame structure, and the dynamic calculation model under earthquake action considering the effect of slope height is established and solved.

(2) The model can clearly describe the influence of the frame structure on the soil and the coupling effect between the creep soil and the prestressed anchors, thus realizing the cooperative work of the frame structure, the soil, and the anchor and ensuring the reliability and safety of the supporting structure. 
(3) The model can reflect the response of prestress and axial force of the anchor, as well as the seismic response of the anchor along the slope height. When considering the effect of slope height, the seismic response of slope body has amplitude difference and delay phenomenon, with significant amplification effect at the top of slope. The acceleration response increases in varying degrees. The axial force response increases significantly at the top of the slope.

(4) The calculation results in this paper are consistent with the dynamic response shown by numerical simulation and shaking table test, which indicates that the calculation model can be applied to the seismic design of reinforced slopes, which provides a basis for the analysis of the seismic response of prestressed anchors with frame structure.

\section{Data Availability}

The data used to support the findings of this study are available from the corresponding author upon request.

\section{Conflicts of Interest}

The authors declare that they have no conflicts of interest.

\section{Acknowledgments}

This research was mainly supported by the National Natural Science Foundation of China (Grant no. 51768040).

\section{References}

[1] G. Behrouz, J. A. Danial, H. Mohsen, and M. Masound, "Prediction of seismic slope stability through combination of particle swarm optimization and neural network," Engineering with Computers, vol. 32, no. 1, pp. 85-97, 2016.

[2] Y. X. Wu and Y. F. Gao, "A modified spectral representation method to simulate non-Gaussian random vector process considering wave-passage effect," Engineering Structures, vol. 201, Article ID 109587, 2019.

[3] L. Wang, C. Z. Wu, X. Gu, H. L. Liu, G. X. Mei, and W. G. Zhang, "Probabilistic stability analysis of earth dam slope under transient seepage using multivariate adaptive regression splines," Bulletin of Engineering Geology and the Environment, 2020.

[4] Z. X. Chen, P. Yang, H. L. Liu, W. G. Zhang, and C. Z. Wu, "Characteristics analysis of granular landslide using shaking table model test," Soil Dynamics and Earthquake Engineering, vol. 126, Article ID 105761, 2019.

[5] Y. X. Wu, Y. F. Gao, L. M. Zhang, and J. Zhang, "How the distribution characteristics of soil property affect probabilistic foundation settlement: from the view of the first four statistical moments," Canadian Geotechnical Journal, 2019.

[6] S. Ye, G. Fang, and X. Ma, "Reliability analysis of grillage flexible slope supporting structure with anchors considering fuzzy transitional interval and fuzzy randomness of soil parameters," Arabian Journal for Science and Engineering, vol. 44, no. 10, pp. 8849-8857, 2019.
[7] S. H. Ye, Y. P. Zhu, D. Q. Wang et al., "Seismic interaction analysis model and seismic response analysis of frame-prestressed anchor-soil system," China Civil Engineering Journal, vol. 47, no. 5, pp. 102-109, 2014, in Chinese.

[8] J. H. Dong, Y. P. Zhu, and W. Ma, "Study on dynamic calculation method for frame supporting structure with prestress anchors," Engineering Mechanics, vol. 30, no. 5, pp. 250-258, 2013, in Chinese.

[9] M. Yan, Y. Xia, T. Liu, and V. M. Bowa, "Limit analysis under seismic conditions of a slope reinforced with prestressed anchor cables," Computers and Geotechnics, vol. 108, pp. 226-233, 2019.

[10] Y. X. Wu, Y.F. Gao, N. Zhang, and F. Zhang, "Simulation of spatially varying non-Gaussian and non-stationary seismic ground motions by the spectral representation method," Journal of Engineering Mechanics, vol. 144, no. 1, Article ID 04017143, 2018.

[11] S. Okamoto and C. Tamura, "Behavior of subaqueous tunnels during earthquakes," Earthquake Engineering and Structural Dynamics, vol. 1, no. 3, pp. 253-266, 1973.

[12] O. Kiyomiya, "Earthquake-resistant design features of immersed tunnels in Japan," Tunnelling and Underground Space Technology, vol. 10, no. 4, pp. 463-475, 1995.

[13] D. K. Shukla, P. C. Rizzo, and D. E. Stephenson, "Earthquake load analysis of tunnels and shafts," in Proceedings of the Seventh World Conference on Earthquake Engineering, vol. 8, pp. 20-28, Istanbul, Turkey, September 1980.

[14] S. Okamoto, C. Tamura, K. Kato, and M. Hamada, "Behaviors of submerged tunnels during earthquakes," in Proceedings of the Fifth World Conference on Earthquake Engineering, vol. 1, pp. 544-553, Rome, Italy, June 1973.

[15] C. Tamura and T. Suzuki, "A quasi-three-dimensional ground model for earthquake response analysis of underground structures-construction of ground model," Monthly Journal of the Institute of Industrial Science, University of Tokyo, vol. 39, no. 1, pp. 37-40, 1987.

[16] C. Li, Y. Yuan, P. He, J. Yuan, and H. Yu, "Improved equivalent mass-spring model for seismic response analysis of two-dimensional soil strata," Soil Dynamics and Earthquake Engineering, vol. 112, pp. 198-202, 2018.

[17] Y. N. Wang, X. Y. Zhang, Y. W. Yuan, and J. H. Wang, "Comparison of seismic analyses by finite element method and equivalent mass-spring method on immersed tube tunnel," Chinese Journal of Underground Space and Engineering, vol. 7, no. 5, pp. 869-876, 2011.

[18] Q. Tan, H. Tang, L. Fan et al., "In situ triaxial creep test for investigating deformational properties of gravelly sliding zone soil: example of the Huangtupo 1\# landslide, China," Landslides, vol. 15, no. 12, pp. 2499-2508, 2018.

[19] Q. Xu, Y. Yuan, Y. Zeng, and R. Hack, "Some new prewarning criteria for creep slope failure," Science China Technological Sciences, vol. 54, no. S1, pp. 210-220, 2011.

[20] S. Zhang, W. Liu, and H. Lv, "Creep energy damage model of rock graded loading," Results in Physics, vol. 12, pp. 11191125, 2019.

[21] F. Wu, J. Chen, and Q. Zou, "A nonlinear creep damage model for salt rock," International Journal of Damage Mechanics, vol. 28, no. 5, pp. 758-771, 2019.

[22] Y. X. Hu, Earthquake Engineering, Earthquake Press, Beijing, China, 1998, in Chinese.

[23] J. Duan, Study on Mechanical Behaviors and Characteristics of Slope Anchorage System with Frame Supporting Structure, Lanzhou University, Lanzhou, China, 2014, in Chinese. 
[24] M. Paz, Structural Dynamics Theory and Calculation, Earthquake Press, Beijing, China, 1993.

[25] S. Ye, G. Fang, and Y. Zhu, "Model establishment and response analysis of slope reinforced by frame with prestressed anchors under seismic considering the prestress," Soil Dynamics and Earthquake Engineering, vol. 122, pp. 228-234, 2019.

[26] S. H. Ye, Z. F. Zhao, and Y. P. Zhu, "Large-scale shaking table model test of loess slope supported by frame anchors," Rock and Soil Mechanics, vol. 40, no. 11, pp. 4240-4248, 2019, in Chinese. 